\title{
Remedial works against debris flows after floods in the State of Vargas, Venezuela
}

\author{
P. Di Pietro ${ }^{1}$, G. Morassutti ${ }^{2}$ \& G. Fracassi ${ }^{3}$ \\ ${ }^{I}$ Maccaferri, Italy \\ ${ }^{2}$ Consultant, Italy \\ ${ }^{3}$ Maccaferri Brasil
}

\begin{abstract}
The catastrophic torrential events occurred in the State of Vargas, on December $15^{\text {th }}$ and $16^{\text {th }}, 1999$, resulted in one of the most important disasters of the $20^{\text {th }}$ century in Venezuela. The extraordinary high magnitude of such weather events caused vast areas to collapse with devastating debris flows in several watersheds. The scope of this work is to present the experience of Corpovargas (Corporación para la Recuperación y Desarrollo del Estado Vargas), in the years 2002 and 2003 in the State of Vargas and to provide useful guidance for other similar cases.
\end{abstract}

\section{Background}

Risk minimization and control structures in the water courses of the State of Vargas, were subject to a first assessment in the year 2000. The design criteria used were again reviewed in 2002 , to verify the validity of the initial assumptions.

Among the design alternatives considered for the mid reaches of the watersheds, the choice was made to use silt retention gabion weirs, due to a) their cost effectiveness, b) large availability of rock material on site, c) possibility to create job opportunities necessary to the economic re-growth of the region [1] and finally, d) the fact that the construction of gabion works does not require specialized labor or equipment.

Based on these requirements, the works involved two types of control structures: selective weirs to catch the large debris allowing fine sediments to flow through, and closed weirs to retain the fines. The need to retain sediments 
was due to the progressive hydro-geological unbalance of vast areas of the watersheds. More importantly, the large amount of sediments discharged on the river estuaries in proximity of the sea, had already induced flooding and heavy siltation to some of the bridges being part of the State of Vargas main roadway infrastructure.

The first reconstruction works started in January 2002 with the installation of some siltation weirs. Concurrently, the monitoring of the existing siltation weirs and its canalization in the Quebrada Guanape (September 2001) as well as the siltation weir in the Quebrada Curucutí (April 1991) started.

\section{Remarks on the Quebrada Guanape}

Both the weir and the canalization were built in concrete. The open selective weir (Fig.1) was to retain large debris (average diameter $\mathrm{d}_{\mathrm{m}} \geq 0.80 \mathrm{~m}$ ) and to let the fines flow through. The steep gradient and low roughness of the concrete channel downstream was to allow the fines to flow till the outlet section into the sea.

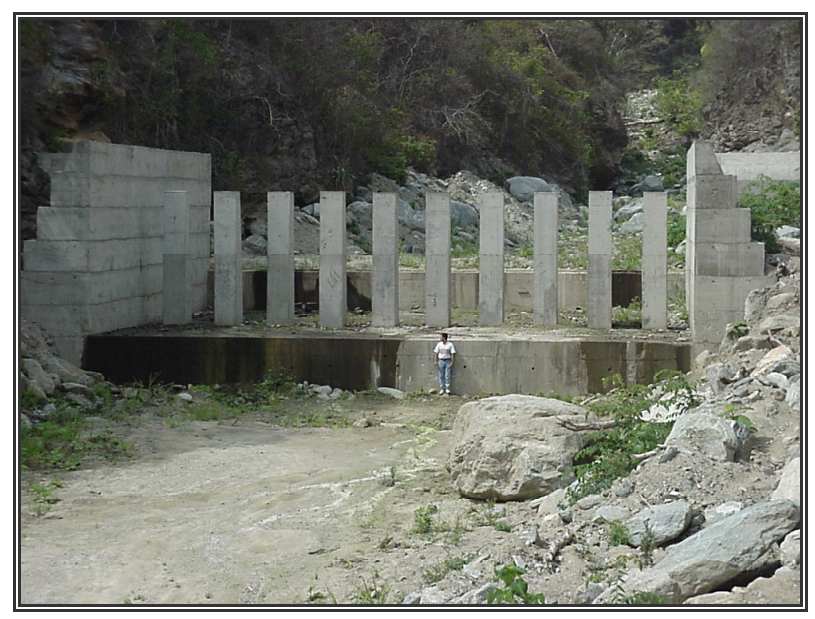

Figure 1: $\quad$ Guanape Weir (September 2001).

However, in January 2002 observations showed that the weir's "teeth" were already clogged by branches and fine sediments, holding up the fine sediments, causing a total siltation upstream (Fig. 2).

The cause is to attribute to the dense vegetation and to the massive presence of fine sediments $\left(\mathrm{d}_{\mathrm{m}}<100 \mathrm{~mm}\right)$, easily erodible even with low to medium discharges.

Therefore the selective weir did not significantly perform as expected since it unexpectedly needed frequent maintenance on the upstream reaches, undesirable for the extra costs and related aspects. Even the downstream canalization, designed with gradients steep enough to enable sediments to flow till the sea, did 
not provide the desired results. The reduced gradient in its downstream reach (Av. Soublette) reduced the flow velocity favoring sedimentation (Fig. 3), and a loss of channel flow conveyance.

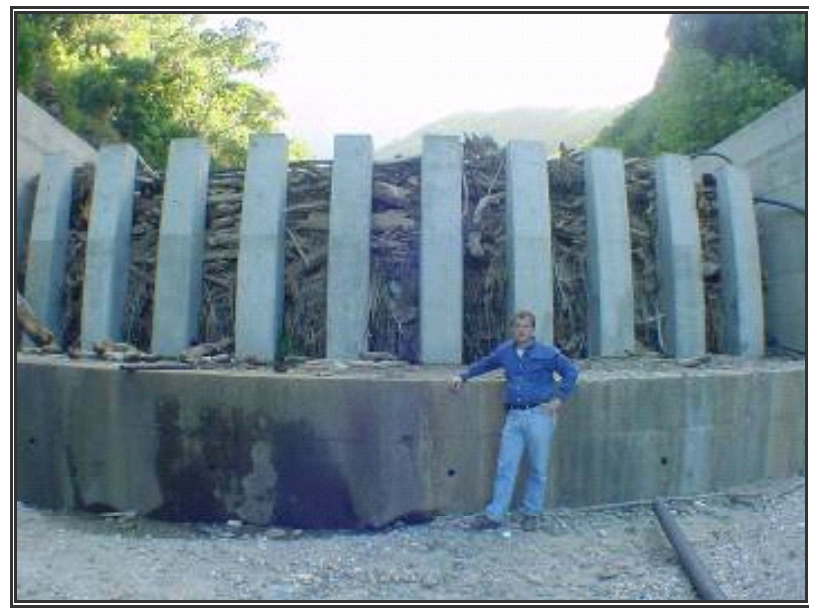

Figure 2: $\quad$ Guanape Weir (February 2002).

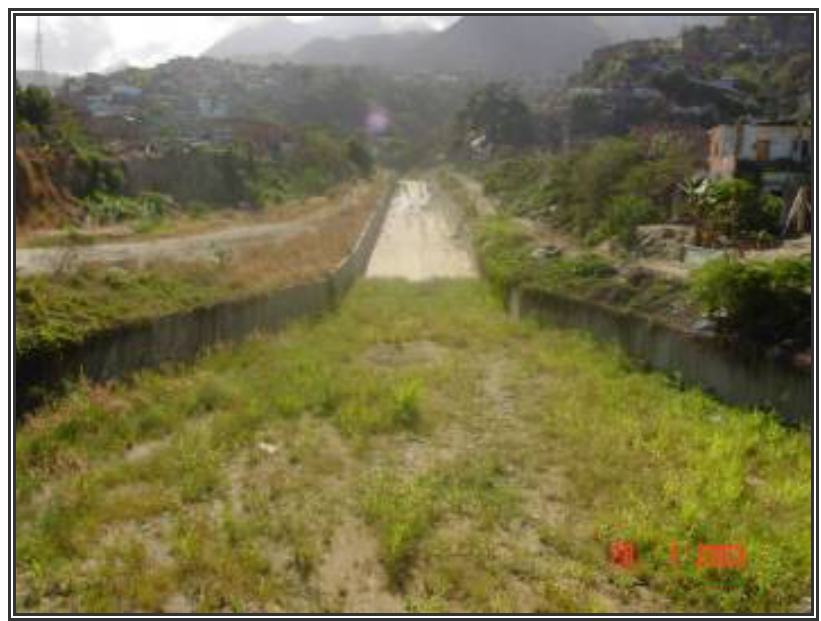

Figure 3: Canalization of the Guanape creek (January 2003).

\section{Remarks on the Curucutì Weir}

At the time of the December 1999 flood, the only river basin with an existing siltation gabion weir built in 1991 was the Quebrada Curucutí. The structure was the first one (on the downstream side, adjacent to the urban area) of four similar works to be successively built along the river. During the December 1999 event, 
both the weir and the entire watershed were only partially affected by damage, since the weir was able to dissipate part of the flow energy when approaching the urban area. Originally designed for a discharge of $70 \mathrm{~m}^{3} / \mathrm{s}(\mathrm{Tr}=100 \mathrm{yrs})$, during the flood the weir underwent an estimated flow of about $120 \mathrm{~m}^{3} / \mathrm{s}(173 \%$ of the design value) (Fig. 4).

Due to the heavy debris, the structure was damaged by excessive abrasion just on the top $2 \mathrm{~m}$ out of its total height of $10 \mathrm{~m}$, that is for just $20 \%$ of the total height, equivalent to just an $11 \%$ of the total volume.

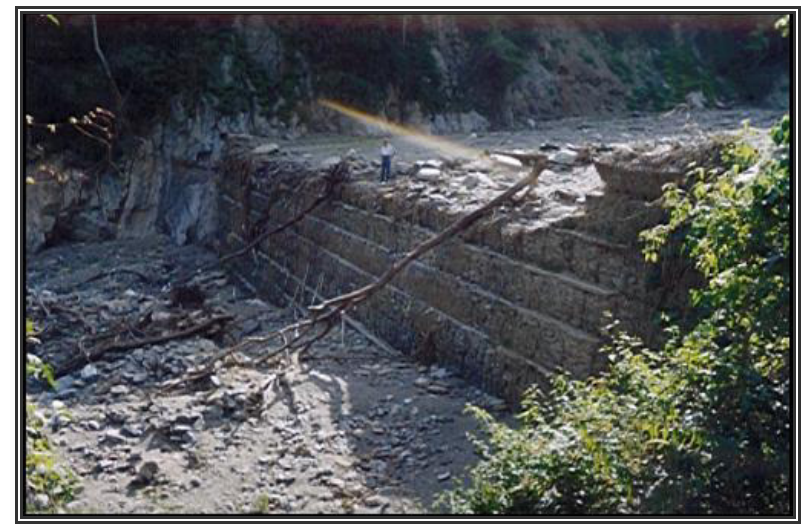

Figure 4: Curucutí weir after the December 1999 flood. The structural damage observed was just on the crest and on the wings.

\section{New Design Criteria based on the Guanape and Curucutì creek's observations}

Based on the observations made in 2002, the selective weirs did not turn to be effective, the reason being primarily due to an improper location, deemed too far downstream on the water course. They would have been likely to perform better if they were located on the middle-high upstream part of the river basin. The alternative solution identified for the low-medium river reach was therefore to build a series of closed weirs instead, in order to progressively retain the fine debris.

Upon completion, a second phase started with the construction of open weirs to be placed closely downstream from the large boulders on the upper river reach. Their function will be to hold them avoiding that they are carried by the flow.

As alternative to the downstream canalization a stepped structure was considered, to reduce the overall river gradient and progressively dissipate the flow energy [5-7]. The structures consisted in gabion channelling works with banks and bottom with variable gradient by means of sills. This option was deemed as the most cost effective and the most compatible with the 
environmental requirements allowing the incorporation of soil bioengineering principles using in-situ material $[3,4]$.

\section{The flood event of February 2005}

Several gabion closed weir structures were built between 2002 and 2003.

In February 2005, another exceptional flood event occurred, even if not disastrous as the one in December 1999, according to the historical annual data for this period of the year [1].

Since continuous rainfall precipitations had occurred from the month of April till December 2004 (Fig. 6) at the time when the event occurred in February 2005 , the soils were saturated resulting in a run off exceptionally higher than the one occurred under normal circumstances. As mentioned earlier, between 2002 and 2003 several control structures had been built along the Curucutí, Osorio, Piedra Azul, Camurí Chico, San José di Galipán, Macuto e Anare creeks. The structures did not show significant damage and performed satisfactorily in relation to the discharges and to the amount of debris (Figs. 5-7).

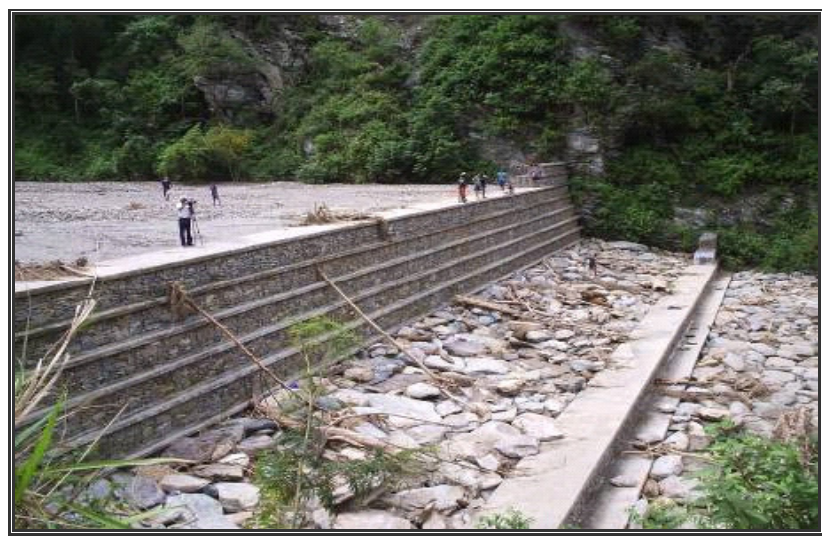

Figure 5: $\quad$ Curucutí Weir. (March 2005.)

\section{The Anare creek}

Particularly relevant was the case of the Anare Creek where siltation weirs and channel lining works to protect a road bridge were used.

Just before the peak of February $10^{\text {th }}, 2005$, on January $8^{\text {th }}$ and $9^{\text {th }}$ a first flood peak hit the Anare creek. Since the river reach upstream from the weir structure was unprotected, the flood favored a meandering effect which resulted in severe erosion and underscouring on the right bank, causing relevant deterioration to the main roadway infrastructure recently rebuilt. (Fig. 8) 


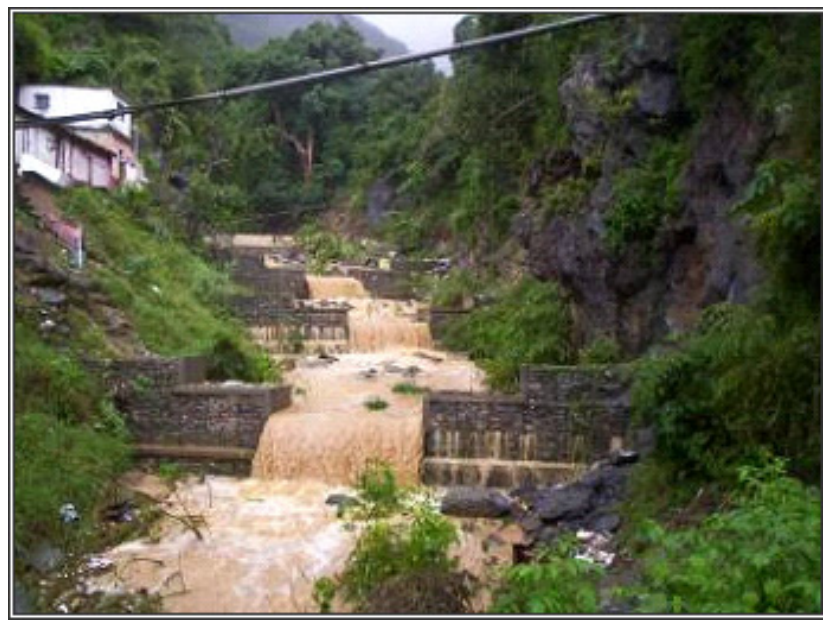

Figure 6: Upstream view of the sills on the Osorio creek. (February $10^{\text {th }}$, 2005.)

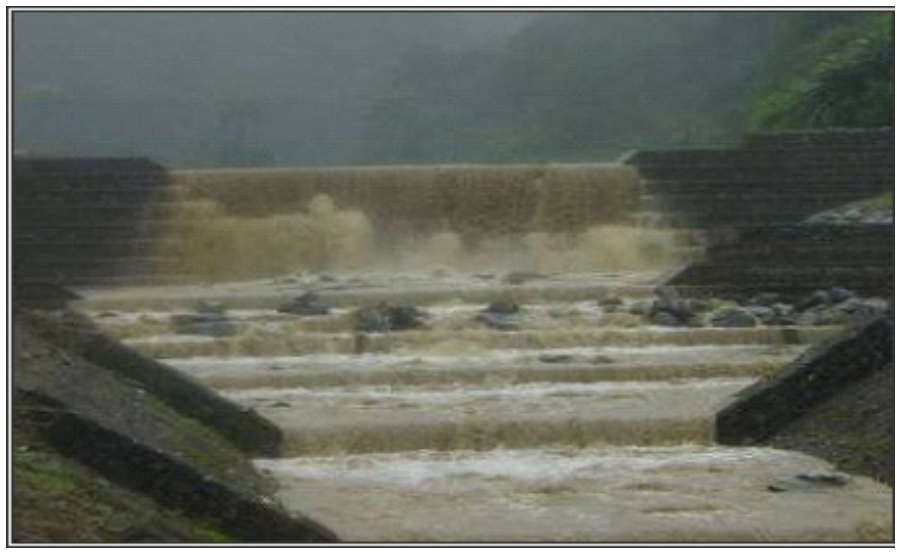

Figure 7: Weir on the Macuto creek. (February, 10 $\left.{ }^{\text {th }}, 2005.\right)$

By hitting right river bank, the flood left the upstream end of the existing canalization vulnerable, amplifying the damages occurred later by the February peak, and creating a sub-flow under the lining which then caused the protection on the right bank to collapse.

In those basins where no training works had been built for lack of funds, much more severe damages occurred. This was the case of the Quebrada Seca, Naiguatá and Camurí Grande creeks. Damages were caused by the large river siltation, until water overflowed the banks (Fig. 9).

Based on observations, notwithstanding the occurrence of more exceptional flood events in a short timeframe, basins where river training works were made no relevant damage were recorded, due to the significant reduction of debris held 
up on the upstream sections which prevented siltation and overflow on the downstream sections. The overall average percentage of damage to the structures used, which required repair works was 1 to $2 \%$ of their total volume.

The experience indicated that the most effective way to mitigate the debris flows in these types of environment may be schematically indicated as in Fig. 10.

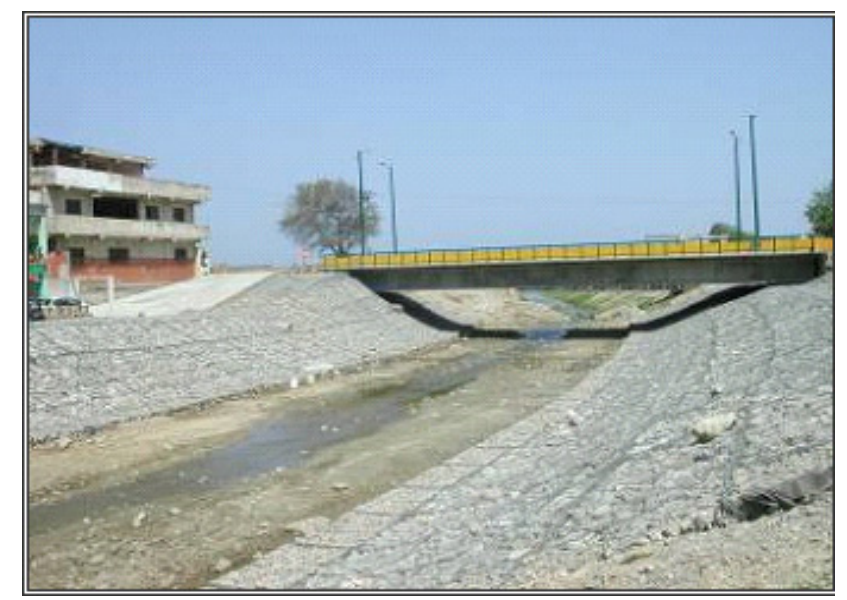

Figure 8: Canalization of the Anare creek near the bridge. (September 2002.)

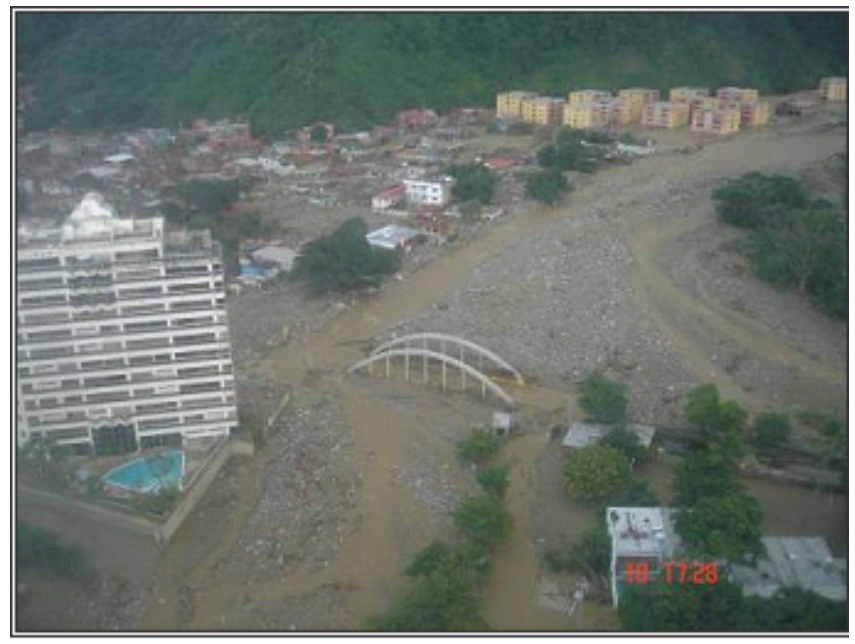

Figure 9: Aerial view of the region in proximity of the Camuri Grande bridge. The river siltation and flooding effects on the banks can be observed. (February 2005.) 


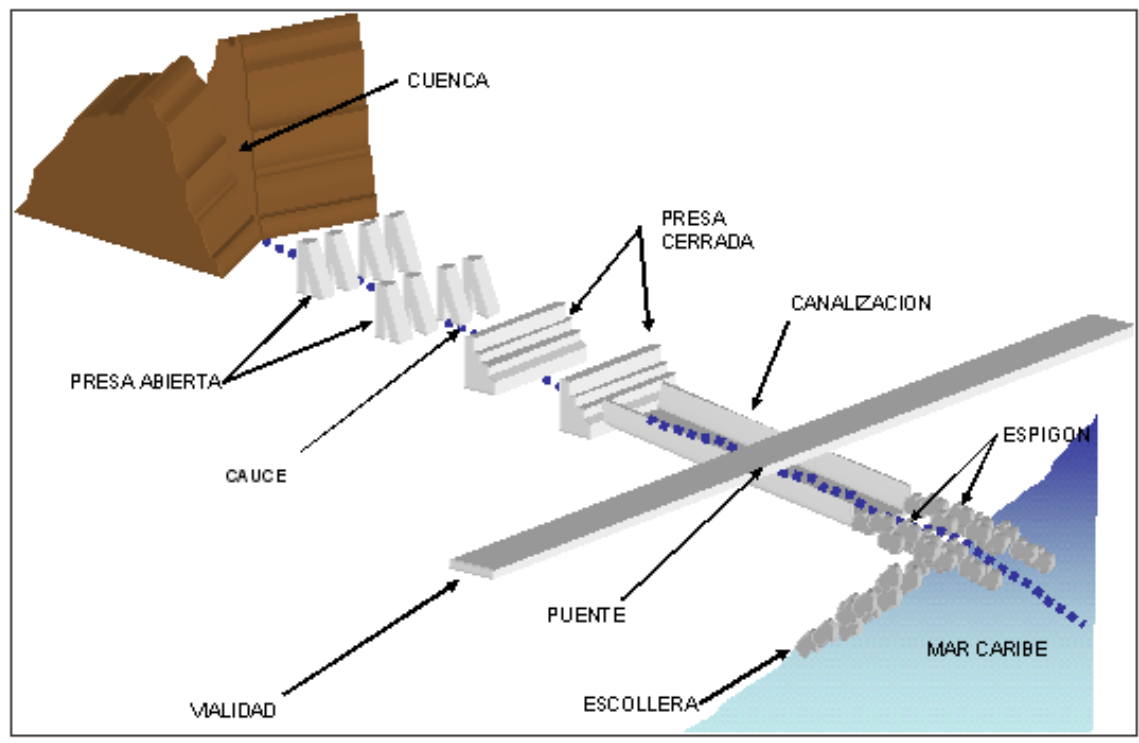

Figure 10: Schematic of the control system of the creeks in the basins.

\section{Conclusions and recommendations}

It shall be noted that the main objective of such works is to minimize the risk of debris flows in urban areas (downstream) through the construction of easily repairable structures in case of necessity.

Due to the December 1999 flood events in the State of Vargas, several siltation weirs and, later on, open selective weirs to catch the large debris were built. This series of works gave satisfactory results as it was then verified during the next event of February 2005 and the urban areas were fairly protected.

Gabion structures allowed overall cost savings of $40 \%$ compared to the initially built concrete and masonry structure. Furthermore, due to their feature of requiring non-specialized labor, they provided the social benefit to employ local labor resources favoring the economy of the region at large scale.

In order to minimize the abrasion phenomena caused by debris and mud flows, the experience showed that it is advised to protect the surfaces directly exposed with masonry or reinforced concrete.

With regard to handling the debris accumulation two are the possible options: the first one is to make periodical maintenance by removing it from the upstream reaches. A second one is to construct further siltation weirs, in order to hold it on the upper middle reaches as much as possible. Based on the overall project long term cost-benefits involved, finally the decision was to implement a fair balance between the two. 


\section{References}

[1] Instituto de Mecánica de Fluidos de la Universidad Central de Venezuela Registros Pluviométricos (2005), Servicio de Meteorología de la Fuerza Aérea Venezolana

[2] C.G.R. Ingeniería. Estudio de Crecidas del Litoral Central del Estado Vargas. Diciembre 2000 - Corpo Vargas, Venezuela

[3] Ven Te Chow - Open-channel hydraulics - McGraw-Hill, New York, 1959.

[4] R.Agostini, L.Cesario, F.Ferraiolo, A.Papetti - Flexible gabion and Reno mattress structures in river and stream training works - section one:weirs - Officine Maccaferri S.p.A.- Italy, 1988.

[5] W. Rand - Flow geometry at straight drop spillways - Paper 791 ASCE, Vol. 81, 1955.

[6] Federal Highway Administration- Hydraulic design of energy dissipators for culverts and channels - Washington, 1975.

[7] H. Chanson - Hydraulic design of stepped cascades, channels, weirs and spillways - Pergamon, Australia, 1994. 